\title{
CORPORDEIDADE E EXISTÊNCIA EM HEIDEGGER
}

\section{DENISE MAGALHÃES DA COSTA ${ }^{1}$}

RESUMO: Nosso objetivo é mostrar o nexo ontológico entre corporeidade e o caráter de existência do Dasein a partir dos Seminários de Zollikon, onde Heidegger correlaciona a corporeidade ao ser-no-mundo; e de Ser e Tempo, onde ele expõe a analítica existencial deste ente e a sua constituição ontológica como ser-em. Nossa hipótese é que a corporeidade é um existencial constitutivo do ser do Dasein e se dá como um modo de ser ôntico-ontológico do ser-no-mundo. Para tanto, pretendemos esclarecer inicialmente a espacialidade ontológica do Dasein e sua co-pertença à corporeidade como um modo do corporar. Em seguida analisaremos os existenciais da compreensão, disposição e fala e seu nexo ontológico com a corporeidade do Dasein. Por fim, apontaremos o caráter ontológico existencial da corporeidade e o corporar do Dasein como um modo de ser deste ente enquanto existência e que se determina no mundo, na relação com os entes, o que confere à corporeidade um caráter ek-stático.

PALAVRAS-CHAVE: corporeidade, existência, corpo, ser-no-mundo, Dasein.

ABSTRACT: Our aim is to present the ontological interconnection between corporeality and Dasein's existential character as from the Zollikon Seminars, where Heidegger correlates corporeity with being-in-the-world; and of Being and Time, where he exposes the analytic existential of this being and its ontological constitution as being-in. Our hypothesis is that corporeality is a constitutive existential of Dasein's being and given as an ontic-ontological mode of being-in-the-world. Therefore, we intend to initially clarify Dasein's ontological spatiality and its co-belonging to corporeity as corporeal mode. Then we will analyze the understanding of existentials, disposition, speech and its ontological correlation with Dasein's corporeality. Finally, we will point out the existential ontological character of corporeality and Dasein's corporeality as a way of being of this entity as existence, and that is determined in the world, in relation to beings, of which confers corporality an ek-static character.

KEYWORDS: corporeity, existence, body, being-in-the-world, Dasein

A questão da corporeidade é pouco explicitada na filosofia heideggeriana. Em Ser e Tempo (1927), encontramos referência à corporeidade do Dasein $^{2}$ em algumas passagens, como, por exemplo, nos parágrafos sobre a espacialidade. O tema foi ainda indicado em outros textos do filósofo tais como, Da Essência da Verdade (1933/34), onde a corporeidade é

\footnotetext{
${ }^{1}$ Professora Adjunta do curso de Licenciatura em Filosofia da Universidade Federal do Recôncavo da Bahia (UFRB). Doutora em Filosofia pela Universidade Federal da Bahia (UFBA). E-mail: magalhaesdenise@hotmail.com.

${ }^{2}$ Na versão brasileira de Ser e Tempo realizada por Márcia Sá Cavalcante Schuback e que utilizamos neste trabalho, Dasein foi traduzido como presença. Entretanto, outros autores traduzem Dasein como ser-aí, estar-aí. Tendo em vista a diversidade de traduções do termo, decidimos mantê-lo em alemão, exceto nas citações.
} 
articulada à existência, assim como em Sobre o Humanismo (1949), também em Nietzsche I (1961) onde encontramos contribuições relevantes para a elucidação da questão da corporeidade. Observamos que essa temática aparece em geral de forma esparsa, porém, significativamente para o esclarecimento da sua concepção de corporeidade.

No entanto, esta temática é mais incisivamente desenvolvida nos Seminários de Zollikon (1959- 1969). Não obstante, nestes Seminários Heidegger se reporta inúmeras vezes a Ser e Tempo, bem como às estruturas ontológicas do Dasein. Assim, por exemplo, lemos nos Seminários de Zollikon, que "O corporar co-pertence sempre ao ser-no-mundo. Ele codetermina sempre o ser-no-mundo, o ser-aberto, o ter de mundo" (HEIDEGGER,2001,p.123). Nesse sentido, se a corporeidade co-determina o ser-no-mundo, constituição fundamental do ser do Dasein, e se este último conceito é melhor desenvolvido em Ser e Tempo, entendemos que as bases para a elucidação da corporeidade encontram-se na analítica existencial. Dessa maneira, para examinarmos a corporeidade do Dasein buscamos pensá-la numa correlação com a existência, com o ser-no-mundo, entre outros caracteres ontológicos do Dasein.

Antes de adentrarmos na questão da corporeidade ressaltamos que a filosofia heideggeriana se contrapõe às concepções tradicionais de homem como um sujeito dotado de corpo e alma ou como animal racional posto que tais concepções determinam de antemão o modo de ser deste ente a partir de uma estrutura dicotômica, qual seja, corpo e razão. Para Heidegger tais determinações são insuficientes para determinar o ser do homem que ele concebe como Dasein, ser-aí, para expressar seu caráter de abertura como compreensão ${ }^{3}$ de ser.

Nesse sentido, no $§ 10$ de Ser e Tempo (1927), encontramos a afirmação que o ser do homem não é uma soma de corpo, alma e espírito (HEIDEGGER, 2006, p.92). Em Da Essência da Verdade (1933/34), que compõe o livro Ser e Verdade, Heidegger nos convoca a libertar-nos da concepção errônea e secular do homem como um animal racional,

\footnotetext{
${ }^{3}$ A compreensão é uma das estruturas ontológicas responsáveis pela abertura do ser do Dasein, e que Heidegger denomina de existenciais, assim como a disposição e a fala. Os existenciais se dão como momentos estruturais indissociáveis, os quais não ocorrem separadamente, mas imbricados uns nos outros. Como compreensão de ser, o Dasein sempre já se compreende de algum modo em seu ser e compreende o ser dos demais entes com os quais se ocupa numa relação de familiaridade. Isto significa que, na cotidianidade, a compreensão não se dá como algo já explícito, mas como pré-compreensão, ou seja, compreensão pré-ontológica, pois não se trata de uma ontologia, não possui uma perspectiva teórica. Isto porque mundo sempre já se abriu numa compreensão e o próprio Dasein, enquanto ser-no-mundo, antes de qualquer tematização. Essa compreensão, por sua vez, é sempre articulada numa interpretação a partir da qual os entes vêm ao encontro do Dasein em seu ser como isto ou aquilo através da posição prévia, visão prévia e concepção prévia. A posição prévia refere-se à compreensão implícita que fundamenta a interpretação cotidiana em que o Dasein já sempre se situa em seu ser-lançado no mundo; na visão prévia o compreendido na posição prévia é apropriado segundo possibilidades de interpretação; na concepção prévia o que foi compreendido na posição prévia e assumido na visão prévia se transforma em conceito através da interpretação. (Cf.: HEIDEGGER, Ser e Tempo, p. 211).
} 
corroborando que: "Não se deve construir e edificar a razão sobre o corpo do homem, mas a corporeidade deve ser deslocada e transferida para a existência” (HEIDEGGER, 2007, p.187). Ser como existência diz o modo de ser do Dasein como um ente que se relaciona com o ser, compreende ser, o seu ser e o ser dos demais entes. Como compreensão de ser, o Dasein é o único ente que se relaciona com o seu corpo como sendo seu, ou melhor, como sendo ele mesmo,“... só o Dasein existe seu corpo e ensaia todo movimento como o que lhe concerne. [...]."(CARON, 2008,p.315, tradução nossa). Assim, pensar o ser corporal do homem como corporeidade, significa pensá-lo não como uma "matéria", que seria o corpo, e uma "forma", que seria o espírito, alma ou razão, mas como um ser "inteiro" que se determina corporalmente como um modo de ser (DASTUR, 2003). Na concepção heideggeriana o "nosso"corpo (Leib), nunca é simplesmente um corpo material (Körper), é sempre o corpo de um Dasein e diz respeito a ele mesmo. ${ }^{4}$

[...] o corpo é, em cada caso, meu corpo. Isto faz parte do fenômeno do corpo. O "meu" é relacionado a mim mesmo. Com "meu", quero dizer "eu". O corpo está no "eu" ou "eu" estou no corpo? Em todo caso o corpo (Leib) não é alguma coisa, algum corpo material (Körper), mas sim todo corpo, isto é, o corpo como corpo é o meu corpo em cada caso. (HEIDEGGER, 2001, p.114)

Podemos observar neste trecho, que Heidegger refere-se ao corpo como "meu corpo", como "eu". Nesta referência ao corpo como "eu", encontra-se indicada, de alguma maneira, a sua concepção de corporeidade. Isto é, na medida em que ao referir-se ao seu corpo como "meu" corpo, ele está se referindo a ele mesmo como "eu", enquanto Dasein que é, isto significa que o corpo encontra-se implicado no seu ser, se dá como corporeidade, apresenta um caráter ontológico. Podemos dizer então que o corpo do Dasein é um modo de ser que copertence aos demais modos de seu ser-no-mundo, isto é, o modo da corporeidade.

Sublinhamos, contudo, que o caráter ontológico do ser corporal do Dasein não significa uma negação de seu aspecto ôntico, afinal o Dasein é um ente que, como compreensão de ser, possui um caráter ôntico-ontológico e, como tal, existe concretamente no mundo, se ocupa com as coisas e se relaciona com os outros em sua cotidianidade.

\footnotetext{
${ }^{4}$ Nos Seminários de Zollikon, Heidegger distingue o corpo material (Körper), em seu aspecto biológico, do corpo vivenciado (Leib). Dessa maneira, o termo "Leib" é usado para designar o corpo vivido, experienciado, como "meu", isto é, como o que diz respeito a mim mesmo, não como algo simplesmente biológico; e o termo "Körper" é utilizado para designar o corpo em seu aspecto material, como geralmente é tratado pelas ciências médicas. "Sem dúvida também se pode examinar o corpo (Leib) como um corpo material (Körper), e como os senhores, como médicos com formação em anatomia e fisiologia..." (HEIDEGGER, Seminários de Zollikon, p.111).
} 
Entretanto, o corpo pode, em certa medida, ser tomado numa perspectiva simplesmente material, isto em uma atitude artificial, objeto das ciências. De qualquer maneira, Heidegger não nega o corpo do Dasein, necessário para a sua relação com os entes nas atividades cotidianas. Mas o corpo (Körper), tratado em seu âmbito fisiológico, por si só, não é o que possibilita a relação do Dasein com os entes em mundo. Afinal, o que seria o fisiológico sem a abertura compreensiva do Dasein para relacionar-se com o seu corpo como seu, e assim encontrar-se com os outros entes? Decerto que o Dasein relaciona-se com o outro corporalmente, mas isso não se dá primordialmente a partir dos sentidos do corpo. O âmbito fisiológico não é uma condição suficiente, uma vez que não é o fisiológico que fundamenta a abertura relacional do Dasein ao mundo e ao outro, mas sim a sua abertura pré-compreensiva ao ser e ao mundo.

O fisiológico é uma condição necessária para a possibilidade de uma relação humana com o outro. No entanto [...] não há um órgão sensorial para aquilo que se chama 'o outro'. [...] A relação existencial não consiste de moléculas, não é originada por elas, mas não existe sem aquilo que pode ser re-interpretado como acontecimento fisiológico-molecular. Se o fisiológico fosse o fundamento do humano deveria haver, por exemplo, 'moléculas de despedida'. (HEIDEGGER, 2001, p.178/179)

Ora, se não é o fisiológico que fundamenta a abertura relacional do Dasein com os entes, mas sim a sua abertura pré-compreensiva ao ser e ao mundo, essa abertura, contudo, não é possível sem o seu ser corporal, e nem se dá antes dele, numa instância, digamos que, supra-sensível, etérea, descorporificada. Mas, porque o ôntico não se dá em separado do ontológico na filosofia heideggeriana, ${ }^{5}$ o termo "corporeidade", refere-se à sua co-pertença aos modos de abertura do Dasein enquanto existência e, portanto, à sua constituição ser-nomundo. Mas então perguntamos: como pensar o ser corporal do Dasein nessa perspectiva da existência como corporeidade?

Podemos visualizar melhor a corporeidade e seu nexo com a existência no caráter ontológico da espacialidade do Dasein e nos existenciais que o estruturam enquanto abertura, principalmente a disposição e a compreensão.

O caráter ontológico espacial do Dasein diz respeito ao modo como ele se direciona para o mundo, aproxima e distancia os entes em suas ocupações. Nessa perspectiva, o Dasein sempre já se encontra junto aos entes e com outro Dasein. Assim, deixar e fazer vir ao

${ }^{5} \mathrm{O}$ caráter ôntico do Dasein significa que em sendo, no exercício de seu ser em suas ocupações no mundo, está em jogo o seu próprio ser. Como compreensão de ser, o Dasein, em sua existência ôntica, relaciona-se com o seu próprio ser e com o ser dos demais entes, possuindo assim um caráter ôntico-ontológico. 
encontro o ente em uma ocupação possui o caráter de aproximação. Aproximar um ente, por sua vez, não diz respeito a um movimento em que o Dasein traz o ente para um intervalo menor de distância do seu corpo, antes, refere-se ao seu caráter ontológico espacial como distanciamento, diz suprimir a distância, ou seja, tornar próximo no sentido de ocupar-se, entreter-se, envolver-se. Enquanto ser espacial, o Dasein vai ao encontro do ente, não como uma "coisa corpórea", ele não percorre distâncias métricas, mas se espacializa, traz o ente para a sua proximidade na medida em que se ocupa e se envolve de alguma maneira com ele. Assim, como exemplifica Heidegger em Ser e Tempo, o quadro que o Dasein vê pendurado na parede acha-se mais próximo do que os óculos que ele carrega no nariz. Do mesmo modo, o chão que toca a sola dos pés ao caminhar encontra-se mais distante do que o amigo que vem ao encontro por esta mesma estrada. (HEIDEGGER, 2006, p.161) Isto quer dizer que não é com os óculos nem com a estrada que o Dasein encontra-se ocupado, junto a, mas encontra-se ocupado junto ao quadro e ao conhecido que vem em sua direção. Nessa perspectiva, o estar junto ao ente numa espacialização pode se dar de diversas maneiras, como por exemplo, com o amigo ouvindo a sua voz em uma conversa ao telefone, junto à paisagem que se vê retratada numa obra de arte, ou ao tema de uma palestra que se ouve e presta atenção. Nesses casos exemplificados, o ouvir, o ver, o prestar atenção sempre se dão numa compreensão, por exemplo, do que se vê, ouve, presta atenção e está junto como modos do corporar. Por conseguinte, dis-tanciar o ente em uma espacialização, tornar próximo, com ele ocupar-se, é um modo do corporar.

Nessa perspectiva é que, ao espacializar-se em seus direcionamentos e distanciamentos enquanto corporeidade, o Dasein deixa e faz vir ao seu encontro o ente numa ocupação a partir de um "lá", do mundo circundante, mundo mais próximo e familiar, de onde retorna para o "aqui" da sua ocupação. No entanto, o "lá" não possui um caráter extensivo, a alguns metros daqui; nem o "aqui" se refere ao lugar que o corpo do Dasein se encontra localizado. "Lá" diz o lugar de onde o ente vem ao encontro do Dasein numa ocupação e junto ao qual ele primordialmente se encontra e se compreende em um "aqui" da relação estabelecida, a cada vez, em suas ocupações com os entes. Sobre isso nos Seminários de Zollikon, Heidegger coloca a seguinte questão:

Onde está o meu corpo quando eu estou 'de corpo e alma' no tema do debate? Por outro lado, como está o tema do debate no espaço? Estou no tema, ouvindo. 'Sou todo ouvidos'. O ouvir é, portanto, o modo do corporar, a participação do corporar na conversa. [...] Tenho, pois, justamente, de ficar sentado na cadeira corporalmente para poder ser todo ouvidos. Se estivesse correndo pela sala não poderia fazer isso ou, pelo menos, não poderia fazê-lo tão bem. (HEIDEGGER, 2001,123) 
Vejamos que, como corporeidade, é efetivamente o Dasein quem está sentado na cadeira. Não se diz, por exemplo, cotidianamente, algo como: meu corpo está sentado na cadeira. Diz-se sempre: eu estou sentado na cadeira. Dessa maneira, é preciso, como no exemplo citado, que o Dasein esteja sentado na cadeira para poder estar atento a uma palestra, uma aula, ou uma conversa, corporando. Por sua vez, quanto mais envolvido o Dasein estiver com o tema da palestra, menos o "seu" corpo estará evidenciado para ele. Tal modo de ser diz respeito à concepção heideggeriana do corpo do Dasein como fenômeno, ou seja, neste caso, o fenômeno da corporeidade. O fenômeno da corporeidade diz respeito ao modo de ser ôntico-ontológico do Dasein no qual o "seu” corpo encontra-se na maioria das vezes velado. É porque a corporeidade se dá como fenômeno, como um modo de ser, que o corpo do Dasein pode ficar oculto quando ele está totalmente envolvido em uma ocupação. É nesse sentido também que o "aqui" não é determinado pelo lugar onde o corpo do Dasein se encontra, mas pelo horizonte do corporar, ou seja, pelo ente junto ao qual o Dasein se encontra, a cada vez, numa ocupação. Isto significa que o "aqui" se modifica constantemente de acordo com o que o Dasein se encontra envolvido e com quem se relaciona a cada circunstância em sua espacialização como corporeidade.

Ao deixar e fazer vir os entes ao seu encontro em suas ocupações o Dasein vê, ouve, fala, toca, isto significa que a sua sensorialidade encontra-se implicada na relação que ele estabelece com o mundo. Sublinhamos, contudo, que não é o olho, por si só, como órgão fisiológico responsável pela visão, que vê. O olho não vê o copo em cima da mesa, talvez enxergue cores, volumes; quem vê o copo é o Dasein porque compreende aquele objeto como copo. Também não é o ouvido que ouve, mas o Dasein. Este ver e ouvir algo, em compreendendo, é um modo do corporar do Dasein, diz um modo como o "seu" corpo, ou melhor, a sua corporeidade, co-participa de sua relação com os entes no mundo com a sua sensorialidade.

- Nessa perspectiva, podemos dizer que Heidegger não nega o caráter corpóreo do Dasein, os sentidos do corpo co-participam do corporar, visto que suas funções biológicas e sensitivas são significadas, ganham sentido pela circunvisão da compreensão, ou seja, no ver e ouvir encontra-se também uma compreensão de ser. "O corporar está em toda parte onde participa a sensorialidade, mas aí está sempre, também, já a primária compreensão-do-ser.” (HEIDEGGER, 2001, p.212) Isto significa que nos exemplos citados, o ver e o ouvir são modos da sensorialidade do Dasein, dos seus sentidos corporais. No entanto, o fato deles se determinarem sempre em uma compreensão do que é ouvido e visto, eles se caracterizam 
como modos do corporar, revelam o modo de ser do Dasein como corporeidade. Dito de outra maneira, o corporar se caracteriza nesses exemplos como um ouvir e ver em compreendendo e, assim, dizem um modo como a corporeidade co-participa da espacialização do Dasein, do estar junto ao ente em uma ocupação. A capacidade sensorial do corpo de ouvir e ver não é suficiente para que o Dasein esteja junto a algo, isto é, para que possa relacionar-se consigo mesmo e com o mundo. Nem tampouco um ser espiritual, descorporificado, pode relacionarse com os entes no mundo. Todos os modos da espacialização do Dasein em que participa a sua sensorialidade também participa a corporeidade em seus diversos modos do corporar. $\mathrm{O}$ corporar pode ser traduzido como um modo de ser do ser-no-mundo enquanto corporeidade.

- Entendemos que o termo "sensorialidade" utilizado por Heidegger, ao invés de "órgãos dos sentidos" refere-se aos sentidos corporais do Dasein como fenômeno, ou seja, ao caráter ontológico em que eles se manifestam como um modo de ser do Dasein em sua corporeidade, sempre perpassados pelo compreender, como um modo do corporar e não simplesmente como função de ouvir e ver fisiológicos. Assim, não só o ver, mas também o ouvir são sempre ver e ouvir numa compreensão de ser, e por isto são modos de corporar. O ouvir compreensivo se dá no modo da escuta. É nesse sentido que em Ser e Tempo é dito:

\footnotetext{
'Em primeiro lugar', nunca escutamos ruídos complexos acústicos. Escutamos o carro rangendo, a motocicleta. Escuta-se a coluna marchando, o vento do Norte, o pica-pau batendo, o fogo crepitando. Somente numa atitude artificial e complexa é que se pode 'escutar' um 'ruído puro'. Que escutamos primeiramente motocicletas e carros, isso constitui, porém, um testemunho fenomenal de que a presença [Dasein], enquanto ser-no-mundo, já sempre se detém junto ao que está à mão dentro do mundo e não junto a 'sensações', cujo turbilhão tivesse de ser primeiro formado para propiciar o trampolim de onde o sujeito pudesse saltar para finalmente alcançar o 'mundo'. Sendo, em sua essência, compreensiva, a presença [Dasein] está desde o início, junto ao que ela compreende. (HEIDEGGER, 2006,p.212)
}

O ouvir, como caráter da escuta compreensiva, de que trata Heidegger em Ser e Tempo, como abertura da fala, é visto nos Seminários de Zollikon como um modo do corporar. De certa forma, podemos dizer então que a questão da corporeidade já se encontra implícita na analítica existencial. O Dasein ouve a motocicleta, o carro rangendo ou o fogo crepitando, porque se encontra junto aos entes, numa compreensão de ser, como corporar, corporando. Esse ouvir, como uma escuta compreensiva, é um modo do corporar. O corpo, simplesmente, não ouviria a motocicleta, mas talvez apenas "ruídos e complexos acústicos." $\mathrm{O}$ existencial da compreensão co-pertence à corporeidade e co-determina o ser-no-mundo em sua existência ôntica, fática, como modos do corporar.

Tendo em vista que, enquanto aberturas do Dasein, os existenciais são estruturas ontológicas indissociáveis, toda compreensão se encontra afinada em uma disposição, termo 
este que é conhecido onticamente como humor ${ }^{6}$. Assim também, toda disposição possui a sua compreensão, mesmo que esta não se dê de modo explícito para o Dasein. "O humor revela “como alguém está e se torna"”. (HEIDEGGER, 2006, p.193)Dessa maneira, o existencial da disposição não apenas diz respeito a abertura do Dasein para o mundo e para o modo de encontrar-se a cada vez em suas ocupações afinado em um humor, como também diz respeito a sua abertura para o ser enquanto possibilidades de projeção de modos de ser. Isto significa que em suas ocupações cotidianas, em suas diversas relações com os entes e com o outro, o Dasein encontra-se afinado em um humor, mesmo que dele não se dê conta. Na medida em que o Dasein é co-determinado pelo humor no qual ele se encontra afinado, e a corporeidade diz um modo de ser do Dasein em suas relações com os entes no mundo, podemos dizer que o humor e a corporeidade são existenciais que co-determinam o modo de ser do Dasein. Assim, o encontrar-se desta ou daquela maneira em uma afinação de humor também co-determina os modos do corporar, isto é, os modos de ser e estar do Dasein enquanto corporeidade.

Nesse sentido é que podemos observar cotidianamente que compreendemos, em certa medida, como o outro se encontra afinado em um humor. Isto porque ontologicamente o Dasein é ser-com, isto é, os outros co-participam da constituição de seu ser na medida em que constituem mundo em sua significância, e assim também constituem o seu ser-no-mundo. Enquanto ser-com, o Dasein sempre compreende o ser do outro a partir da compreensão que tem de seu próprio ser e também compreende de alguma maneira o modo de ser corporal do outro, o modo como o outro se encontra afinado em um humor, em seus gestos, seu tom de voz, seu olhar triste ou alegre, entre os modos de ser que desvelam o outro em sua corporeidade, isto é, no seu corporar.

Todos os modos de ser do Dasein se determinam no mundo, ou seja, enquanto ser-nomundo o Dasein sempre se encontra em mundo, com o outro e junto aos entes, isto é eksistência ${ }^{7}$. Dessa maneira, tendo em vista que a corporeidade co-pertence à existência e esta se dá como ek-sistência, então podemos dizer que a corporeidade co-pertence à ek-sistência. Por isto que os modos em que o Dasein se encontra afinado em um humor podem ser, de certa

\footnotetext{
${ }^{6}$ A palavra humor é a tradução de Márcia Schuback do termo alemão Stimmung, que é traduzido também por tonalidade afetiva. Na nota 47 de Ser e Tempo a tradutora explica que "valeu-se igualmente da expressão 'afinação do humor' de modo a indicar que o 'humor' significa uma estrutura de afinação e sintonização. Não se valeu nem de tom e nem de tonância, pois ambos referem-se ao resultado da afinação ao passo que, em Ser e Tempo, trata-se do movimento verbal mesmo de afinar-se, sintonizar-se enquanto abertura do 'humor'.'SHUBACK. Márcia Sá Cavalcante. Notas Explicativas; In.: (HEIDEGGER, 2006, p. 573).

${ }^{7}$ Como abertura para o ser e para o mundo o Dasein existe desde sempre lançado no mundo, para onde se projeta compreensivamente em suas ocupações. Nesse sentido, para realçar este aspecto Heidegger grafa o termo "existência" como ek-sistência, referindo-se ao caráter ontológico de abertura do Dasein como um ente que se projeta para o mundo, encontra-se sempre "fora", no mundo. Todavia, o "fora" possui um sentido ontológico, referindo-se a abertura do Dasein para o ser, ao caráter ek-stático, do Dasein.
} 
maneira, compreendidos por outro Dasein, que, como ser-com, encontra-se desde sempre num mundo compartilhado. Sobre o modo de ser e estar do Dasein em uma afinação de humor, Heidegger (2000, p.91) afirma:

O sentimento como um sentir-se é, precisamente, a maneira como somos corporais; ser corporal não significa que um apêndice chamado corpo é simultaneamente ligado à alma, mas no sentir-se o corpo está desde o princípio co-inserido em nosso sipróprio e, com efeito, de um modo tal que ele permeia a nós mesmos em seu estar em tal ou tal estado. Não 'temos' um corpo assim como portamos a faca na bolsa; o corpo também não é um corpo físico que apenas nos acompanha e que também constatamos aí ao mesmo tempo, expressamente ou não, como simplesmente dado. $\mathrm{O}$ sentimento, como sentir-se pertence à essência desse ser. $\mathrm{O}$ sentimento efetua de antemão a inserção implicativa do corpo em nossa existência.

Daí, podemos inferir que o sentir-se desta ou daquela maneira implica o ser corporal do Dasein como co-determinante do seu ser si-mesmo. É no existencial da disposição que o corpo do Dasein, como afirma Heidegger, é co-inserido em seu si-mesmo, como corporeidade. Diante disso, podemos dizer que a corporeidade co-pertence ao si-mesmo, coparticipa da constituição do Dasein como ser-no-mundo.

Entretanto, sublinhamos que o humor não diz respeito a um estado de alma de um sujeito, ele não possui um caráter interior, subjetivo. Os existenciais são estruturas ontológicas que se determinam "fora", no mundo. A disposição abre um modo de ser e estar do Dasein no mundo, afinado em um humor, a cada vez, nas suas relações com os entes, antes de qualquer conhecimento teórico, de qualquer reflexão e independe da sua vontade.

\footnotetext{
A disposição é tão pouco trabalhada pela reflexão que faz com que a presença [Dasein] se precipite para o 'mundo' das ocupações numa dedicação e abandono irrefletidos. O humor se precipita. Ele não vem de 'fora' nem de 'dentro'. Cresce a partir de si mesmo como modo de ser-no-mundo.(HEIDEGGER, 2006, p.196)
}

O ser-com é partilhado 'expressamente' na fala. [...] O que se pronuncia é justamente o estar fora, isto é, o modo cada vez diferente da disposição (ou do humor) que, como se indicou, alcança toda a abertura do ser-em. $\mathrm{O}$ índice linguístico próprio da fala em que se anuncia o ser-em da disposição está no tom, na modulação, no ritmo da fala, 'no modo de dizer'. [...] A fala é a articulação em significações da compreensibilidade inserida na disposição do ser-no-mundo.

O humor se anuncia faticamente na fala através do tom, da modulação, do ritmo e do modo de dizer os pronunciamentos, o que nos indica a co-pertença do existencial da fala à corporeidade de cada Dasein, como modos do corporar. Caso contrário, todos pronunciariam da mesma maneira, e em qualquer circunstância. Os mecanismos fisiológicos das cordas vocais não dão conta desse fenômeno, eles não explicam os modos como a cada vez o Dasein se pronuncia, antes, é a sua constituição ser-no- mundo, o compreender, a disposição e a 
corporeidade que expõem os modos como a cada circunstância, um Dasein se pronuncia e se determina em seus modos de ser no mundo. Mais uma vez podemos verificar que a questão da corporeidade encontra-se implícita na analítica existencial. A corporeidade diz respeito à copertença do ser corporal do Dasein à existência, ela co-determina o ser-no-mundo.

Por sua vez, na medida em que, enquanto ser-no-mundo, o Dasein sempre se encontra em mundo, com o outro e junto aos entes, a corporeidade, como um modo de ser que copertence à existência, também se determina fora, em mundo, na ek-sistência, como modos do corporar. Entendemos que Heidegger imprime à corporeidade um caráter ek-stático na medida em que se refere ao corporar como um modo de ser do Dasein determinado na abertura do mundo, em sua relação com os entes. É nesse sentido que os movimentos corporais do Dasein, os seus gestos e o seu tom de voz, por exemplo, dizem um modo do corporar, ou seja, um modo de ser e estar seu, enquanto corporeidade, e que se abre nas suas relações com o mundo, no modo como ele é afinado em um humor, numa compreensão de ser, ou seja, no modo como ele é afetado por mundo enquanto ek- sistência. Assim, de acordo com Heidegger (2006,p.244),

[...] tudo o que chamamos a nossa corporeidade, até a última fibra muscular e a molécula hormonal mais oculta, faz parte essencialmente do interior do existir; não é pois, fundamentalmente matéria inanimada, mas sim um âmbito do poder perceber não objetivável, não opticamente visível de significações do que vem ao encontro, do que consiste todo o Da-sein.

Nesse sentido, podemos dizer que a corporeidade é também um existencial que estrutura o Dasein como ser-no-mundo e, como tal, se determina a cada vez no mundo, como modos do seu corporar enquanto ek-sistência. É nesse sentido que Gilvan Fogel (2010,p.174) afirma, ao referir-se à corporeidade em Heidegger:

A expressão 'corpo humano' deve ser acentuada. O 'humano' é para reforçar que, quando se fala de corpo, em se referindo a homem, homem, já aconteceu, já se fez ou se deu. Mas ele também não se dá antes $e$ fora do corpo, isto é, antes e fora (cronologicamente anterior) de realização, concretização ou que, talvez, se possa denominar encorporação, encarnação. Homem-corpo - isto é o único acontecimento, um único e mesmo instante, um único e mesmo ato este acontecimento um, integro, este único e mesmo ato é dito em e como ek-sistência. 


\section{REFERÊNCIAS BIBLIOGRÁFICAS}

CARON, Maxene. Sur la question du corps dans la pensée de Heidegger: De Sein und Zeit aux Séminaires de Zollikon. Archives de Philosophie, 2008/2 tome 71, p.309-329. Disponível in http://www.carin.info/revue-archives-de-philosophie-2008-2-page-309.htm

CERBONE, David R. Heidegger and Dasein' 'Bodily Nature': what is the Hidden Problematic? In: Heidegger Reexamined. London: Routledge, 2002.

CIOCAN, Cristian. The Question of the Living Body in Heidegger's Analitic of Dasein. Research in Phenomenology, Volume 38, Number 1, BRILL, 2008.

DASTUR, F. Heidegger et la Question Anthropologique. Éditions de L'Institut Supérieur de Philosophie, Louvain-la-neuve, Éditions Peeters, Louvain - Paris, 2003.

FERREIRA, Acylene Maria C. A constituição ontológico-existencial da corporeidade em Heidegger. Síntese, Belo Horizonte, v.37, n.117, 2010, p.107- 123. 108. . Mundanidade e Diferença Ontológica. Síntese, Belo Horizonte, v. 40, n 26, pp.85-

FOGEL, G. A respeito de Homem, de Vida e de Corpo. In: Emmanuel Carneiro Leão. Org. Fernando Santoro...[et al]-1ed Rio de janeiro: HEXIS: Fundação Biblioteca Nacional, 2010,(Pensamento no Brasil:1), p.163-179.

FRANCK, Didier. Chair et corps: Sur la phénoménologie de Husserl. Paris: Editions de Minuit, 1981.

. Heidegger e o problema do espaço. Tradução João Paz, Coleção Pensamento e Filosofia, Instituto Piaget, Lisboa, 1986.

HAAR, M. Heidegger e a essência do homem. Lisboa: Instituto Piaget, 2003.

. Le primat de la Stimmung sur la corporéité du Dasein. In: Heidegger Studies 2, 1986, p. 67-80.

. Le chant de la terre. Paris: L'Herne, 1985.

HEIDEGGER, Martin. Conferências e escritos filosóficos. Trad. Ernildo Stein. São Paulo: Nova Cultural, 1989. (Os Pensadores).

. Nietzsche I. Trad. Juan Luis Vermal. Barcelona: Destino, 2000.

. Nietzsche II. Trad. Juan Luis Vermal. Barcelona: Destino, 2000.

. Ontología. Hermenéutica de La facticidad, Madrid, Alianza Editorial, 1999.

Os problemas fundamentais da fenomenologia, Trad. Marco Antônio Casanova,

Petrópolis, RJ: Vozes, 2012, (Coleção Textos Filosóficos).

. Principios Metafísicos de la Lógica, Traducción de Juan José García Norro, Ed.

Sintesis. Madrid-Espanha, 2009.

Prolegómenos para una historia del concepto de tiempo. Traducción de Jaime Aspiunza, Madri: Alianza Editorial, 2006.

Questions III e IV. Trad. Jean Beaufret, François Fedier, Julien Herver, Jean Lauxerois, Roger Munier, André Préau e Claude Roels. Paris: Gallimard. 1976.

. Ser e Verdade: a questão fundamental da filosofia; da essência da verdade/Martin Heidegger; tradução Emmanuel Carneiro Leão. Petrópolis: Vozes;Bragança Paulista: Editora Universitária São Francisco,2007.(Coleção Pensamento Humano). 
Sobre o humanismo. Trad. Emmanuel Carneiro Leão. Rio de Janeiro: Tempo Brasileiro, 1967.

. Ser e Tempo. Trad. revisada e apresentação de Márcia de Sá Cavalcante Schuback; posfácio de Emmanuel Carneiro Leão. Petrópolis: Vozes, 2006..

. Os conceitos fundamentais da metafísica: mundo, finitude, solidão. Trad. Marco Antônio Casanova. Rio de Janeiro: Forense Universitária, 2003

Seminários de Zollikon. Trad. Gabriela Arnhold e Maria de Fátima Almeida Prado. São Paulo; Petrópolis: Vozes; EDUC, 2001.

LEVIN, David Michael. The Ontological Dimension of Embodiment: Heidegger's Thinking of Being. In.: WELTON,Donn (org.). The body. Massachusetts: Blackwell, 1999. 